\title{
ENSAYO La nueva poesía costarricense
}

\author{
Dr. Adriano Corrales Ariasi, Instituto Tecnológico de Costa Rica \\ Recibido: 11/9/2014 \\ Aprobado: 27/11/2014
}

\section{Resumen}

Este ensayo sobre la poesía costarricense contemporánea surge a partir de algunos artículos y "polémicas" encontradas en algunas publicaciones periódicas y en varias redes sociales. Sin desdeñar el aporte de la academia, se aborda la poesía costarricense contemporánea desde una visión integradora, para mostrar que varios pensamientos considerados como básicos se asientan sobre premisas engañosas y apreciaciones sesgadas, o se encabalgan en prejuicios, denostaciones y defensas de poéticas o nombres específicos, a modo de una incipiente guerrilla literaria. Se anotan tres ejemplos para mostrar que la discusión se ha centrado en el Valle Central costarricense y en el binomio poesía conversacional-poesía trascendentalista, dejando por fuera otras franjas estéticas e ideológicas en el amplio campo literario costarricense. Al final se ensayan algunas conclusiones provisionales.

\section{Abstract}

\section{The New Costa Rican Poetry}

This communication is an essay upon contemporary Costa Rican poetry. Based upon several articles and "debates" published in periodicals and social networks, without disregard for the contributions of the academia, contemporary Costa Rican poetry is discussed from an integrating viewpoint in order to show that the basic considerations taken as the usual point of departure lie upon deceitful premises and biased opinions, or they rest upon prejudice, revilement or the defense of given poetry or specific names in the fashion of an incipient literary guerrilla. Three examples are presented in order to prove that such discussion has been limited to the Central Valley and to the conversational poetry-transcendental poetry binomal, leaving out other aesthetic or ideological strata of the vast Costa Rican literary field. At the end, some provisional conclusions are attempted.

i Adriano Corrales es doctor en Artes y Letras de América Central, graduado de la Universidad Nacional y se desempeña en la actualidad como profesor catedrático en el Instituto Tecnológico de Costa Rica.
Adriano Corrales Arias. La nueva poesía costarricense. Revista Comunicación. Año 35, vol. 23, núm. 2. Julio - diciembre, 2014. Tecnológico de Costa Rica. ISSN Impreso: 0379-3974/ e-ISNN: 1659-3820

\section{PALABRAS CLAVE:}

Poesía costarricense, nueva poesía costarricense, antilirismo, poesía trascendentalista, crítica literaria, realismo sucio.

\section{KEY WORDS:}

Costa Rican poetry, Costa Rican new poetry, antilirism, transcendentalist poetry, literary criticism, dirty realism. 


\section{PREÁMBULO METODOLÓGICO}

Este trabajo pretende aportar insumos teóricos y metodológicos a la discusión en torno a lo que se denomina la "nueva poesía costarricense". El enunciado es ambiguo y problemático, dado que nos remite tanto a rupturas formales como a novedades lingüísticas y temáticas en posturas y propuestas poéticas (cfr. Sánchez), así como a la irrupción de poetas en el panorama de la poesía costarricense contemporánea en un marco de periodización generacional, método siempre discutible e impreciso. Recordemos que en poesía lo nuevo puede ser arcaico y viceversa.

Como no se trata ni de historia ni de historiografía literaria, nos interesa, a partir de algunos artículos y "polémicas" encontradas en publicaciones periódicas y en las redes sociales, abordar la poesía costarricense contemporánea desde una visión integradora (sin desdeñar el aporte de la academia) para mostrar que las consideraciones utilizadas como punto de partida se asientan sobre premisas engañosas y apreciaciones sesgadas, o se encabalgan en prejuicios, denostaciones y defensas de poéticas o nombres específicos a modo de una incipiente guerrilla literaria. Dicho de otro modo, no trascienden el marco de la "crítica" de quienes escriben en suplementos literarios de periódicos o en sitios web de varios de los autores involucrados.

Sin embargo, la posibilidad de un debate serio sobre la cuestión hace que esos prolegómenos sirvan de estímulo e insumo para una efectiva discusión que pudiese aclarar "los nublados del día". El problema estriba en que la crítica académica, en una posición que podríamos llamar "reproductivista" y presuntamente "científica", rehúye el meollo de la discusión y se compromete las más de las veces, con el canon señalado por editoriales comerciales, certámenes, festivales internacionales, premios nacionales y panegíricos periodísticos. Por su lado, los autores se refocilan en los egos intramuros de sus blogs o en cortinas de humo de defensas o defenestraciones personales (ataques ad hominem) desde diversas páginas digitales.

Además, se intentará revelar que en el campo literario costarricense, dicha polémica se centra en el advenimiento de una poesía concreta, urbana o conversacional que a veces se presenta como antipoesía o antilirismo, frente a una poesía "trascendentalista" que ocupó, hasta hace poco, la institucionalidad y el canon, favorecida por el establishment cultural. En otras palabras, una dicotomía estilística e ideológica en pugna por la hegemonía del campo artístico (literario) nacional. Pero también se pretende mostrar que existe "otra" poesía, novedosa, sugerente e incluso iconoclasta, que no es tomada en cuenta para los debates académicos ni periodísticos y más bien sufre de una tendencia que pretende ocultarla y hasta obviarla como objeto de estudio o como ejemplo de poéticas emergentes por su aesthesis ${ }^{1}$. Lo anterior pasa por una suerte de "vallecentrismo" literario y cultural que margina las producciones poéticas de la periferia costarricense. Se expondrán, brevemente, tres ejemplos.

\section{LA POLÉMICA}

"El antilirismo costarricense" expuesto por Fernández (2012) procuraba reflexionar y aportar algunas consideraciones sobre las franjas ideoestéticas contemporáneas. Según el autor, a partir del año 2000 hay una nueva hornada de poetas que, dado el agotamiento institucional y artístico del "Trascendentalismo" (cfr. Albán, 1977), enarbolan nuevas banderas a partir de la "antipoesía" del chileno Nicanor Parra (1914 - ) y del "realismo sucio" del estadounidense de origen alemán Charles Bukowski (1920-1994). Al respecto, Fernández afirma que:

No se trata, sin embargo, solo de un diálogo ocasional con la antipoesía y el realismo sucio, sino de una reelaboración que tiene su propio modo de representarse. Podríamos llamarla "poesía concreta con enfoque antipoético" (o antilirismo costarricense) porque tampoco es un calco de la antipoesía y mantiene su independencia (Fernández, 2012).

Además, este autor (Fernández, 2012) afirma que el antilirismo costarricense:

Es una tendencia que se contrapone a lo siguiente:

a. A la expresión de los poetas del trascendentalismo, mediante el empleo de un lenguaje coloquial y casi libre de connotaciones metafóricas.

b. A los herederos del trascendentalismo, muchos de estos reunidos en talleres literarios.

c. A la herencia de la poesía de Jorge Debravo y de algunos representantes de su generación que no fueron trascendentalistas, sino expresionistas o surrealistas.

d. A los poetas suscritos en otras tendencias que no son las anteriores y que podrían haber sido puntos 


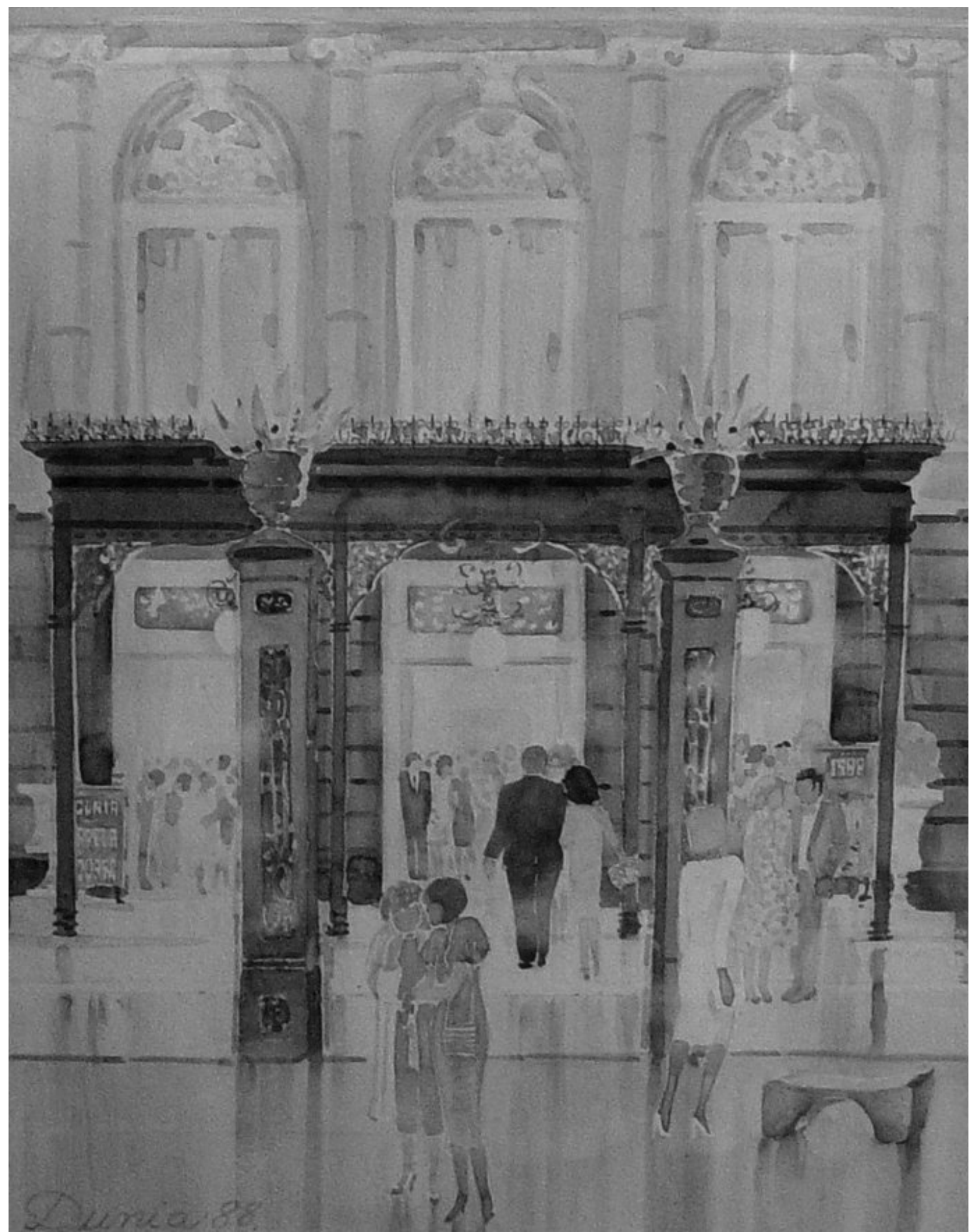


de partida muy sugestivos de ellos mismos, como, por ejemplo, Jorge Arturo, Jorge Treval (alguna de su poesía mezcla realismo sucio y aspiración revolucionaria) y Carlos Cortés, entre otros.

El cuarto punto resulta relevante para el presente análisis, pues expresa la claridad que hubo en los precursores de las nuevas tendencias, ya olvidados por los protagonistas del "antilirismo". Entre ellos destacan Jorge Arturo Venegas Castaing (1961-2005) quien pretendía desembarazar la palabra poética del lastre de las retóricas tradicionales (trascendentalistas, sí), en una búsqueda de frescura y naturalidad para propiciar el diálogo con el lector, es decir, darle estatus poético a lo simple, cotidiano y coloquial; David Maradiaga (1968-1995) quien apostó a la comunicación política, casi como continuidad de Jorge Debravo, pero sin rehuir lo metafórico ni el rigor métrico dentro de una urdimbre existencialista, casi expresionista, con una poesía fresca y actual; Mario Matarrita (1951 - ) cuya poesía pregunta las identidades culturales a partir de la añoranza por las raíces campesinas del costarricense medio y la decadencia sociocultural urbana. Hay más y podemos ir hacia atrás en su búsqueda: Mayra Jiménez (1939 - ), Juan Antillón (1940 - ), Alfonso Chase (1944 - ), Joaquín Soto (1946 - ), Virginia Grütter (1929-2000), Carmen Naranjo (1928-2012), Mario Picado (1928-1988), Antidio Cabal (1925-2012), Alfredo Sancho (1924-1990), Francisco "Paco " Amighetti (1907-1998), Joaquín Gutiérrez (1918-2000), Isaac Felipe Azofeifa (1909-1997), Rafael Estrada (1901-1933), Max Jiménez (1900-1947), entre otros. Y, por supuesto, Jorge Debravo (1938-1967), quien parte aguas en la poesía nacional y resulta sujeto de culto, discordia y ataque de muchos de los poetas "nuevos"; acaso sin él y sin su obra mucha de la poesía ciudadana, civil, contestataria y conversacional, no habría podido posicionarse.

Las características de la nueva poesía, su "antilirismo", según Fernández (2012), serían las siguientes:

a. Desencanto por las acciones de la política.

b. Desacralización de los emblemas religiosos y sobre todo culturales.

c. La bohemia como valor.

d. Vigencia del malditismo, pero como pose vital, sin entrar en filosofías.

e. El método periodístico como forma de escribir. f. Empleo de lenguaje coloquial y desenfadado."

A esos elementos, Fernández (2012) añade cierto "decadentismo" y reúne a un grupo de poetas costarricenses que cumplen con ellos: Luis Chaves, María Montero, Felipe Granados, Paula Piedra, Ricardo Marín, Faustino Desinach, Juan Hernández y Gustavo Chaves, entre otros. El problema con esta solución es que se reúne en un mismo grupo a varios poetas que no necesariamente provienen de la "antipoesía" ni del "realismo sucio", aunque se ubican en una franja más amplia que algunos investigadores denominan sencillamente "poesía urbana" o "conversacional" (narrativizante y coloquial), contrapuesta a una poesía trascendentalista o más bien, "aurática, de carácter abstracto metafísico" (Rodríguez, 2006).

Lo anterior lleva a equívocos que provocan discusiones bizantinas, como la generada por el artículo del poeta Marco Aguilar (Jiménez, 2013), producto de una mala lectura del artículo de Fernández (2012). Aguilar enfunda a todos los poetas jóvenes de San José en un realismo sucio macabro y moralmente obsceno. Imprudente generalización que provocó que la polémica iniciada antes derivara más hacia un problema ético o político que hacia el problema estético, mismo que ciertamente cuenta a la hora de discutir sobre poesía. En la discusión se perciben dos presupuestos de la crítica académica tradicional y de la doxa literaria:

a. Poéticas diversas ubicadas en un mismo lugar y tiempo con una visión lineal de la historia, por ende de la literatura y del hecho poético (lo generacional).

b. Insistencia en la relación autor-obra y en la inmovilidad textual, sin que se comprenda a cabalidad la dinámica creadora en el corpus de un mismo poeta, ni tampoco la intertextualidad y los genotextos, o sea, las relaciones entre enunciados en un espacio temporal mucho más amplio que los segmentos generacionales: el dialogo permanente entre ruptura y tradición, tal y como lo señalaba Octavio Paz (1987).

Y es que la literatura y el arte se articulan a lo interno de sistemas de significación mayores. Las lecturas posibles de un poema o de un libro se entrecruzan con un entramado de otros textos socioculturales, políticos y económicos que tienen lugar en el contexto de su producción y en el sistema-mundo global. Por eso, comprender la literatura y la poesía como proceso o como dinámica en un cronotopo diferenciado, sea en 
un campo cultural específico con asimetrías temporales y espaciales y con pugnas por el poder simbólico y material, es intentar una mirada amplia a una poesía que, como la costarricense, posee alturas y llanuras, mesetas y abismos, montañas y playas, lugares soleados y oscuros. Así, por ejemplo, se ha construido un abismo entre el Valle Central y el resto del país que, en términos de políticas culturales y de circulación de textos literarios no cuenta: lo que se produce en el Gran Área Metropolitana (GAM) es lo que representa a la nación. Hay un vallecentrismo poético exclusivo y excluyente, además de un dualismo invisibilizador de otras corrientes (culturalismo, neoexpresionismo, neobarroco, minimalismo, sensualismo, feminismo, y otras) y de la heterogeneidad discursiva.

\section{TRES EJEMPLOS}

El primer ejemplo puede verse en el caso de Francisco Rodríguez Barrientos (1956. Él es poeta, ensayista, narrador, profesor e investigador universitario. Además de su primer y único libro de poesía Sobrevivencia del agua (1996) ha venido produciendo una vasta e inexplorada obra en el terreno del aforismo ${ }^{2}$, género menor para algunos, venido a menos para muchos y casi no frecuentado en la literatura costarricense, centro y latinoamericana. Lo mismo había hecho Max Jiménez (1900-1947) con sus Candelillas (1946, publicada en 1978) o textos híbridos como Unos Fantoches (1928), De la vida (i1926?, publicada en 2004) y El Domador de pulgas (1936), donde se armonizan, el relato, la fábula y el aforismo.

La poesía de Rodríguez, cercana al haiku o haikai japonés, a la poesía clásica china, o la clásica náhuatl, es una rareza en nuestro medio:

$$
\begin{gathered}
\text { El agua } \\
\text { sobrevive } \\
\text { a todas las palabras } \\
* * * \\
\text { ¡La rama...! } \\
\text { Ahora seca } \\
\text { Puede } \\
\text { al fin } \\
\text { quebrarse (1996). }
\end{gathered}
$$

Sus aforismos están muy cercanos a este tipo de poemas. Rodríguez los emplea para expresar una gama de ideas, sentimientos y emociones, y los entrelaza con el poema, el relato breve, la sentencia, el análisis y la bitácora de viaje, sin dejar de lado el sarcasmo, la acidez y la crítica sociopolítica y cultural.

De esa manera ha producido una voluminosa obra que cuenta con seis volúmenes y vienen más. Ello da fe de una búsqueda intensa por caminos poco recorridos contemporáneamente con espíritu indagador y cuestionador, porque, como dice una de sus sentencias, "Los exploradores no tienen por qué llegar a conclusiones" (2006).

Lo primero por subrayar es la pluralidad temática de Rodríguez y su interés intelectual y existencial. Lo segundo es la capacidad de diálogo con y a través de sus autores favoritos, quienes le proporcionan material de reflexión, análisis y perspectivas de crecimiento e innovación, así como nuevas vías de interpretación. "Los grandes autores son los que nos ayudan a descubrir", anota (2006), y ese diálogo propicia en los lectores la oportunidad de terciar en sus descubrimientos: asertos, sarcasmos, inquietudes y proposiciones, expuestos con ternura, rabia, pasión, mesura, cinismo, humor, erotismo e imaginación.

Lo tercero es la variedad paisajística de su escritura: ciudades, pueblos, aposentos, sitios de encuentro de Costa Rica, Centroamérica, el Caribe y Latinoamérica. Igual sucede con el paisaje humano: dioses, escritores, artistas, pensadores, políticos, reformadores, gobernantes, dictadores y subalternos con gendarmes y el grotesco torturador de turno. Por supuesto, aparecen las víctimas y excluidos de un sistema global que privilegia el mercado ante las auténticas relaciones humanas.

He allí un esfuerzo sostenido de poética variada en matices, intensidades, temas y formas; un brío enciclopédico que hurga en lo mejor de la cultura universal y en los miasmas y aristas más agudas de nuestra identidad y de nuestras historias. No desdeña las culturas populares, ni las masivas, sino que las conjuga con una erudición propia de las culturas de élite. La suya es una obra totalizadora de un escritor que, a fuerza de estudio, observación, reflexión y producción, ha devenido en un escritor cosmopolita y ecuménico. Esta lúcida y poco frecuente trayectoria aforística es la más profusa y lograda ya no solo de nuestro país, sino del ámbito americano, hasta donde tenemos noticia. La cuestión entonces es: ¿cuántas personas la conocen? 


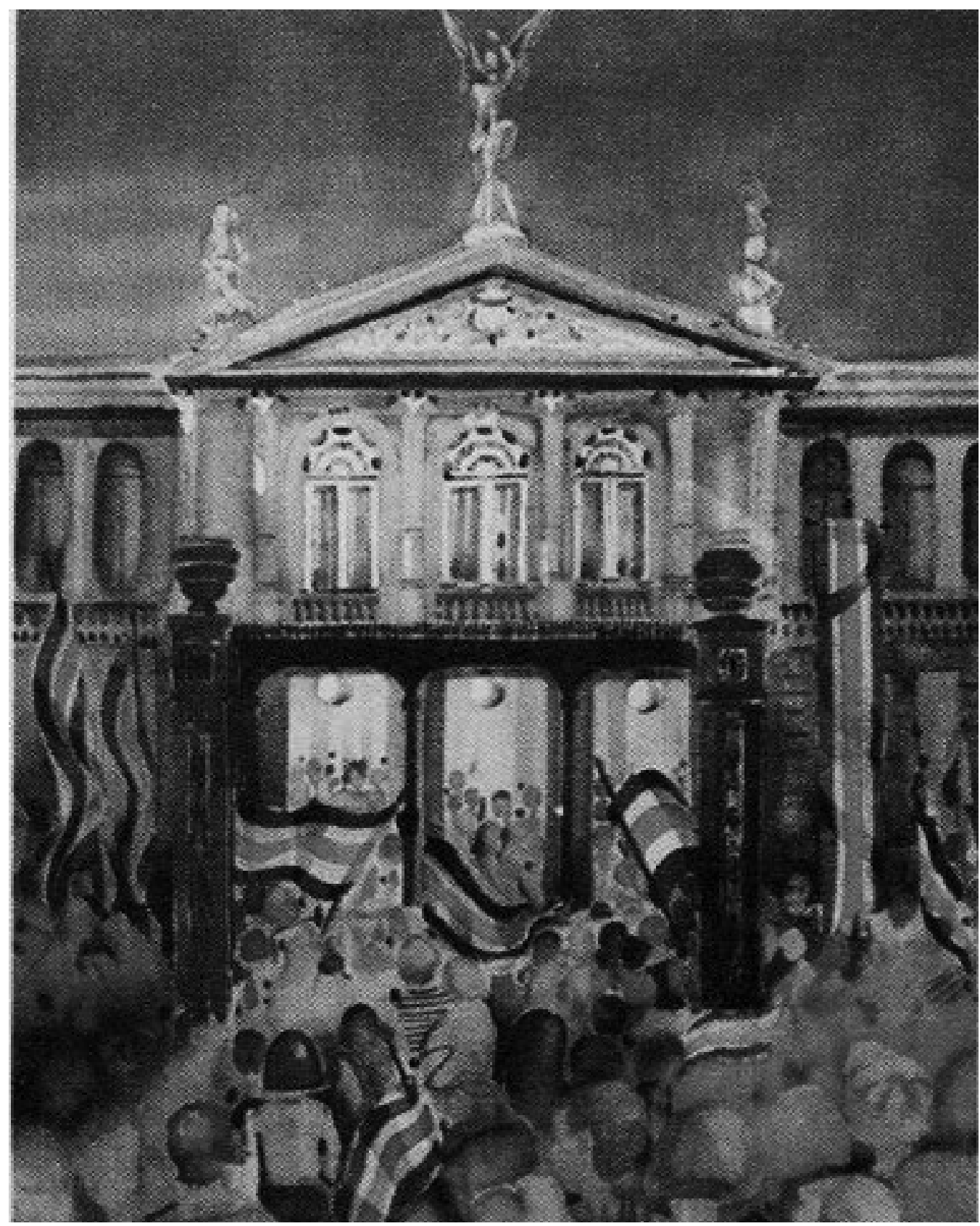

Dunia Molina M.

\section{DOS}

Un raro ejemplo de que la literatura posee aperturas temporales en su circularidad o capacidad de saltar y sucederse por diversas épocas, es el poemario Expediente (1985), ópera prima y único libro impreso de Joaquín Soto (1946 - ). El autor, médico jubilado de la Caja del Seguro Social Costarricense, se encuentra alejado del quehacer literario (cfr. Durán, 1988 y Vargas, 2006).
¿Qué es lo raro del libro? Lo primero es la forma: al estilo del poeta norteamericano Edgar Lee Masters (1868-1950) y de su Spoon River Anthology (1916), el célebre conjunto de 250 epitafios en verso libre y en forma de monólogo dramático, inspirados en un cementerio pueblerino imaginario de su Illinois natal. Joaquín Soto por su parte, ubica sus expedientes en un hospital imaginario de su valle de El General para, con lenguaje sencillo y verso libre también, tramar una profunda radiografía de la vida campesina y 
aldeana de sus congéneres, no exenta de crítica social y de reflexión ontológica. Con imágenes tiernas y escalofriantes a la vez, pero siempre poéticas, una serie de personajes reales pero tamizados por sus dicciones nos comunica su soledad, su angustia, su miseria:

Viejo y solo yazgo en un sanatorio con gangrena en un pie:

lo tengo muerto. (Soto, 1985, p. 10)

\author{
¡Caso insólito! \\ Ahora estoy muerta. \\ ¡Mirad mi expediente! \\ Me desangré por dentro: \\ ningún médico lo sospechó (Soto, 1985, p. 9).
}

Esos personajes, al borde de la muerte, o muertos ya, brindan testimonios y dramas íntimos en una tierra olvidada por los planes de ajuste estructural y los negocios off shore de la globalización neoliberal, recluidos o destrozados por la violencia doméstica o estructural. Son monólogos desesperanzadores y rabiosos:

Tuve veintinueve embarazos

y solo cuatro me pegaron.

Los demás fueron abortos,

veinticinco hemorragias

sin ver jamás el hospital.

Un doctor quiso cortarme los tubos

y mi esposo se negó,

también mi madre

y monseñor.

Yo seguí abortando

a lo que Dios dispusiera.

Se venían por cualquier cosa,

con un susto, con un brinco.

Mi esposo los cogía con un papel

y los enterraba en el panteón.

¡He aquí el infierno

al que me condenaron todos!" (Soto, 1985, p. 38).

Los títulos de los poemas tienen una carga semiótica que se potencia con nombres propios al resumir las características del personaje y sus vicisitudes. Igual que Lee Masters, Soto ataca el aldeanismo, la estrechez de miras y su puritana hipocresía moral pero desde una perspectiva doble: la colonial:

Se llamaba Margarita

y deshojó su nombre con desprecio

para llamarse Kenmore como las refrigeradoras de la Sears.

Tenía siete niños de padres diferentes, a cada hombre que sedujo le dio un hijo

con la intención de retenerlo

o conseguir una pensión.

Al hijo mayor le puso Texas,

al siguiente, Mc Gregor como las camisas Ingrid, Katty, Liz y Lesly, son las niñas.

Y al más chiquitín le puso Pops.

Mas Kenmore Pérez

no es culpable de semejante cursilería.

Ella intenta sobrevivir

de la manera más elegante (Soto, 1985, p. 27).

Estamos frente a un libro de ruptura en el plano de la poesía regional (la Zona Sur), y del país en general, que sorprende por su sencillez y audacia, especialmente por abandonar la sensiblería y la consigna cuando de poesía social se trata. Más bien utiliza la parodia y el humor negro sin perder en ningún momento el guiño afectivo:

A los ochenta años siguen enamorados y sus hijos

los pusieron a dormir en cuartos separados.

Ellos se levantan a medianoche

y en el sofá de la sala

se encuentran" (Soto, 1985, p. 26).

Así, se evidencia la colonialidad del poder presente en la visión vallecentrista de la cultura nacional, que excluye casi toda producción de la periferia. Finalizo con un poema estremecedor:

Yo me crié a golpes como los caballos lastimado por el barejón y las piedras de los barrancos.

Comiendo poco, llevé cargas ingratas y pasé frío en el amor. Sí, doctor, ¿por qué tanto examen?

El diagnóstico está claro:

roto a mis 40 años (Soto, 1985, p. 12).

¿Acaso hay aquí realismo sucio?

TRES

Luis Yuré es un autor sui generis y prolífico. Es de suponer que tras el seudónimo se esconde un dotado artista, quien también ha ilustrados las portadas de 
sus libros. Hasta el momento publicado cuatro: Tuanis Opus Palo, Alba en rodajas, Fe de Ratas e Idiaykus.

Al examinar el primer libro se mencionarán algunas características de los demás. Lo primero que Ilama la atención es la desfachatez de la propuesta editorial ("No Hubo", es decir, nadie se animó) en términos de satirizar y cuestionar el mundo institucional de las publicaciones ("ISBN: Sepa judas"; "Chilillo al que lo reproduzca parcial o totalmente") y la pedantería de la academia. Veamos la presentación del autor en la contratapa:

Luis Yuré ha sido panadero, malabarista, payaso de hospital, curandero (sobador) y locutor de radio. Junto a Gabriela Carobo funda el movimiento de los neuróticos. Padece de un bachillerato en literatura con su desagrado en psicología de MTSU y en la actualidad juega a ser homeópata (2002).

Además, aunque se ridiculizan las tradicionales sinopsis de libros, nos entrega las coordenadas poéticas del mismo:

Tuanis Opus Palo propone un plumaje distinto en el área de la poesía costarricense al utilizar el lenguaje pinta o jerga metropolitana. Esta leve ruptura con los formalismos estéticos reinantes se acentúa gracias a una buena dosis de burla y denuncia, crítica de la que no sale exento nadie, en especial, los payazos [sic] en corbata que manejan el país.

Nótese el uso de la z en la palabra payaso, una constante agramatical en el texto. El libro también fractura los términos de la conversación en la poesía nacional e irrumpe con una frescura renovadora al recuperar la jerga urbana del Gran Área Metropolitana (GAM), sin perder la vistosidad, el colorido y la metaforización, eso sí, con una ácida crítica al status quo y a la institución literatura. Veamos algunos de los títulos interesantes de los poemas, en tanto hallazgos lingüísticos: "Caitemancia", "Pepiados", "Valeverguista", "Oiga Pito", "La depre", "El empiece", "Nos despapayó", "Qué salado", "La divina pelada", "Furris 100 al sur y 25 al oeste", "Lgía del piropo", "Hablada del compa nostálgico mascando chicle", y otros por el estilo.

Seguidamente se reproduce por entero el poema "Don quién, el prolífico" por considerarlo una suerte de ars poetica que resume la propuesta de aesthesis de Yuré:
Me parece empezó rayando grafittis un balbuceo de proverbios, y frases célebres.

Más tarde las hormonas

rimaron por él y entonces sale el 'Kamasutra', y en medio frenesí del insomnio publica 'Las mil y una noches', que siempre ayuda a ruliar.

Luego le picó la épica, y así leímos 'La canción de Roldán`, seguido por 'El mío cid' tan suyo. Por eso

aunque ahora esté en decadencia y haga llamadas obscenas

o escriba cartas de secuestro con recortes de periódico

y viva en las sombras,

don Anónimo siempre será mi escritor favorito.

Igual se transcribe el poema "Lista parcial de zánganos" como muestra de la ácida crítica político y social desenfadada y directa:

De a por dere, casi todos se creen buenos.

La vina del barrio que llega al éxtasis envenenando gatos,

el mostro que alquila niños a los gringos burro de licha

las barras acné de chapulines, candado chino todos se creen buenos.

El lechero que adultera con agua lo que vende, el sorompo que desprecia al prójimo por ser nica, el cura de la radio que comulga tucanes, todos se creen muy buenos.

Los tráficos anteojo mosca, mordida o parte, el coyote sangre hocico aullando de placer, esos ministros lavadólares, todos se creen tan buenos.

Como angelitos de sombra barro, gusanos en el cas con conciencia podrida, tan útiles y zánganos

tan buenos para nada. (Yuré, 2002).

El libro contiene caligramas y requiebres del espacio, listas que dialogan, vocablos nuevos y fulgurantes como "Lgía" y otros provenientes del habla popular. Se copia el fragmento final del poema "La herencia o plan místico para el 23 de junio de 2003" donde se liquida al poeta:

Ahí se los dejo

mi cuello hermanado al nudo de la soga, 
mis muñecas lagrimitas rojas empañando un cuchiIlo,

y la desalmada alma que se destapa, como un frasco vacío de pastillas,

en la mano agusanada del cadáver sonriente de Luis Yuré

¿Habrá (sobre) realismo macabro?

El texto Alba en rodajas (2002) supone un giro hacia una metaforización casi trascendentalista. Pero véase el poema que le da título:

$$
\begin{gathered}
\text { Al romper el huevo } \\
\text { Alba dejó los ombligos } \\
\text { en el cadáver verde de su madre } \\
\text { cinco años después } \\
\text { el himen palpitando tibio } \\
\text { sobre el hueso del padrastro. } \\
\text { Ya en la escuela } \\
\text { descoloran su materia gris } \\
\text { para que se le caiga marchito el cerebro } \\
\text { y le cosen los brazos a una escoba } \\
\text { y le sacan el corazón } \\
\text { para casarla con ese minotauro } \\
\text { que como una lepra } \\
\text { le arranca a golpes la vida } \\
\text { encerrándola en su laberinto } \\
\text { de donde a veces sale } \\
\text { oscura Alba } \\
\text { vestidito negro } \\
\text { anteojos oscuros }
\end{gathered}
$$

La propuesta de aesthesis se profundiza al atacar el centro de la literatura como institución, sobre todo a la academia y al idioma mismo, a partir de una insurrección de letras y palabras: "Gramatanza"

Aunque el golpe bajo vino de la $B$

$$
\text { la A, su cómplice }
$$

se apresuró a asestar azotes casi de inmediato disgustada por perder sus aires de líder

así las siguieron la $\mathrm{C}$ y la $\mathrm{S}$

qué serpentina se enroscó para ahogarla mientras el resto hasta la W extranjera

se mayuscularon graves y atónicas en un gerundio mordiendo, pateando

a matar, a matar gritaban infinitivas. Pero ahí mismo se dio un hiato

cuando vieron con horror como se des-silaba la i que se rompe el puntito quedando en estado de coma.

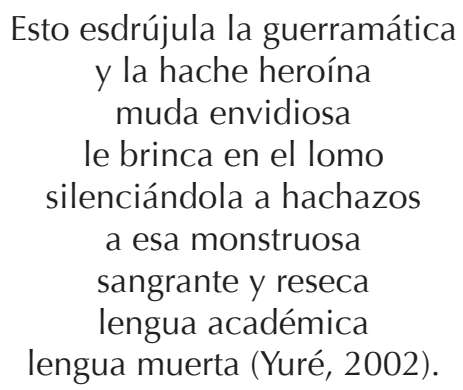

El libro, experimental y rupturista, contiene poemas visuales cual especie de caligramas en luces de neón o televisivos.

Fe de ratas (2009) por su lado, es una apuesta más compleja, y se nos advierte de entrada: "Para escarnios, diatribas, puestas en escena (o mejor aún, propuestas obscenas)". Siguiendo la escritura bíblica del Génesis, pero con profundidad desacralizadora, este texto híbrido deriva en una dramaturgia sui generis (lírica y teatro) y bizarra (como casi toda la producción de Yuré), donde el mito bíblico y sus personajes se entremezclan con aforismos, sentencias, dudas filosóficas y contraculturales: "¿Será siempre más portentosa nuestra miseria, que el dios que concebimos para aplacarla?" (p. 70). O con poemas pasmosos e iconoclastas con cierto humor negro:

29 Lo más agrio de su lepra le cobijaba vino la muerte, el sueño o el orgasmo la oruga de su boca dejó de hilar blasfemias.

Entonces cayeron sus párpados como cuervos abatidos.

Así descansó dios al séptimo día

y desde entonces no despierta. (Yuré, 2009).

Es un texto rico en sugerencias de semiosis con una fractura en el discurso poético nativo al mezclar géneros y dialogar con "libros sagrados" en una franca y enorme irreverencia desmitificadora.

Finalmente Idiaykus (2010) es una colección de haikus, o haikais, criollos en un juego semántico y verbal que nos retrotrae de alguna manera a las Concherías (escritas en 1905) de Aquileo Echeverría (1866-1909) por su temática, pero con lenguaje más "concho" y posmoderno:

En barrio Amón se espabilan dos robles.

Asfalto en flor.

Si es La Sabana

un pulmón. ¿Dónde tiene

Chepe el culo? 


\author{
$* * *$ \\ La jama zen: \\ arroz ying, frijol yang \\ El gallo pinto \\ $* * *$ \\ Labia de títeres \\ Voz de oscuros ventrílocuos \\ Los gobernantes. \\ Dedo en su tinta \\ voto por Chricuto \\ No soy tan bruto (Sobre Chiricuto ¡Ñaaaaa!). \\ $* * *$ \\ Donde hubo ego \\ (hambrienta hoguera del yo) \\ cenizas quedan. (2010).
}

Al final, con sarcasmo, se incluyen cinco "entrevistas" con diferentes personajes que opinan, o refieren, acerca de la vida del "poetiso menor" Luis Yuré, invención de un poeta que no se cita ni se incluye en reseñas ni discusiones sobre poesía costarricense, mucho menos en la academia, y que abreva en el realismo sucio, la antipoesía, el absurdo dadaísta, el mito, lo gótico y el neoexpresionismo. Un verdadero enfant terrible.

\section{A MODO DE CONCLUSIONES PROVISIONALES}

Para profundizar la discusión en torno a la "nueva" poesía costarricense se precisa de una crítica avisada y profesional que dé cuenta de los intertextos, disidencias, desencuentros y diálogos en el ancho cronotopo nacional, para deslindar así las luchas y pugnas en el campo artístico-cultural. Se debe pasar de la microguerrilla de grupos, editoriales, blogs, premios y certámenes a una polémica reflexiva y crítica que alterne con el canon de la academia y de los instituyentes públicos y privados.

Dicha polémica además, debe tomar en cuenta las asimetrías geográficas, temporales y socioculturales para valorar cada producto, su poética y su representatividad en el ancho y dialógico campo artístico/ literario nacional, así como sus ligámenes y discontinuidades con respecto a la región centroamericana, latinoamericana y global. Todo ello con la inclusión de las posibilidades de la mirada poética (de poemas y de lecturas posibles) en torno a las relaciones de poder y la violencia simbólica e institucional representadas o insinuadas, pero, además, los vínculos de poetas y grupos literarios con la autoridad político - cultural constituida. El intento pasa por reconocer los discursos novedosos, tanto en forma como en contenidos o temáticas, primordialmente aquellos que descolonicen semiótica, lingüística y culturalmente los "lenguajes poéticos" y se aventuren a superar lo ingenuo, "corrongo" o realistamente sucio cuyo objetivo es sorprender (épater le bourgeois) y ocupar el primer plano en la foto para los 15 minutos de fama.

La incipiente guerrilla literaria gira en torno a movimientos o propuestas que aglutinan seguidores en forma centrípeta. Primero fue el trascendentalismo que, al ocupar los sitios estratégicos en las instituciones y la academia, logró posicionar su "credo" poético como el hegemónico. Los profesores, jurados y críticos provenían de sus filas y por eso atraían tanto recluta interesado en los bienes culturales simbólicos (publicaciones) o materiales (premios, por supuesto). En un programa televisivo, los poetas Julieta Dobles y Ronald Bonilla sostenían que la excelencia de su taller literario ("Círculo de Poetas Costarricenses") consistía en que casi todos sus miembros poseían un premio nacional. "De hecho, se debe agregar que Dobles lo ha obtenido en cinco ocasiones" (Solórzano, 2010).

A medida que el Trascendentalismo fue perdiendo sostenibilidad, el "conversacionalismo" fue adquiriendo prestigio y poder al ocupar espacios de relevancia aupados por editoriales emergentes que sobrepasaron los círculos cerrados y viciosos de la editorial del estado (Editorial Costa Rica) y de las universitarias, publicaciones comerciales, premios y jurados, además de una tropa electrónica que sistemáticamente fue torpedeando las posiciones trascendentalistas. Se inició una suerte de éxodo (la "Extensa huida", parafraseando el nombre de uno de los poemarios más representativos de ese movimiento (Zárate, 1999) incluso en sus principales representantes. Así, tres de los firmantes (Julieta Dobles, Carlos Francisco Mongey Ronald Bonilla) del "Manifiesto Trascendentalista", excepto su redactor, Laureano Albán, se desmarcaron de los preceptos de la proclama al buscar estrategias representacionales más coloquiales, comunicativas y acordes con "los tiempos que corren" signados por el "conversacionalismo". Tal vez sea "otra modulación (...) mediante una escritura que mezcla los dos niveles de la poética trascendentalista con elementos comparativos de la 
Revista Comunicación. Volumen 23, año 35, núm. 2, julio-diciembre, 2014 (pp. 47-59)

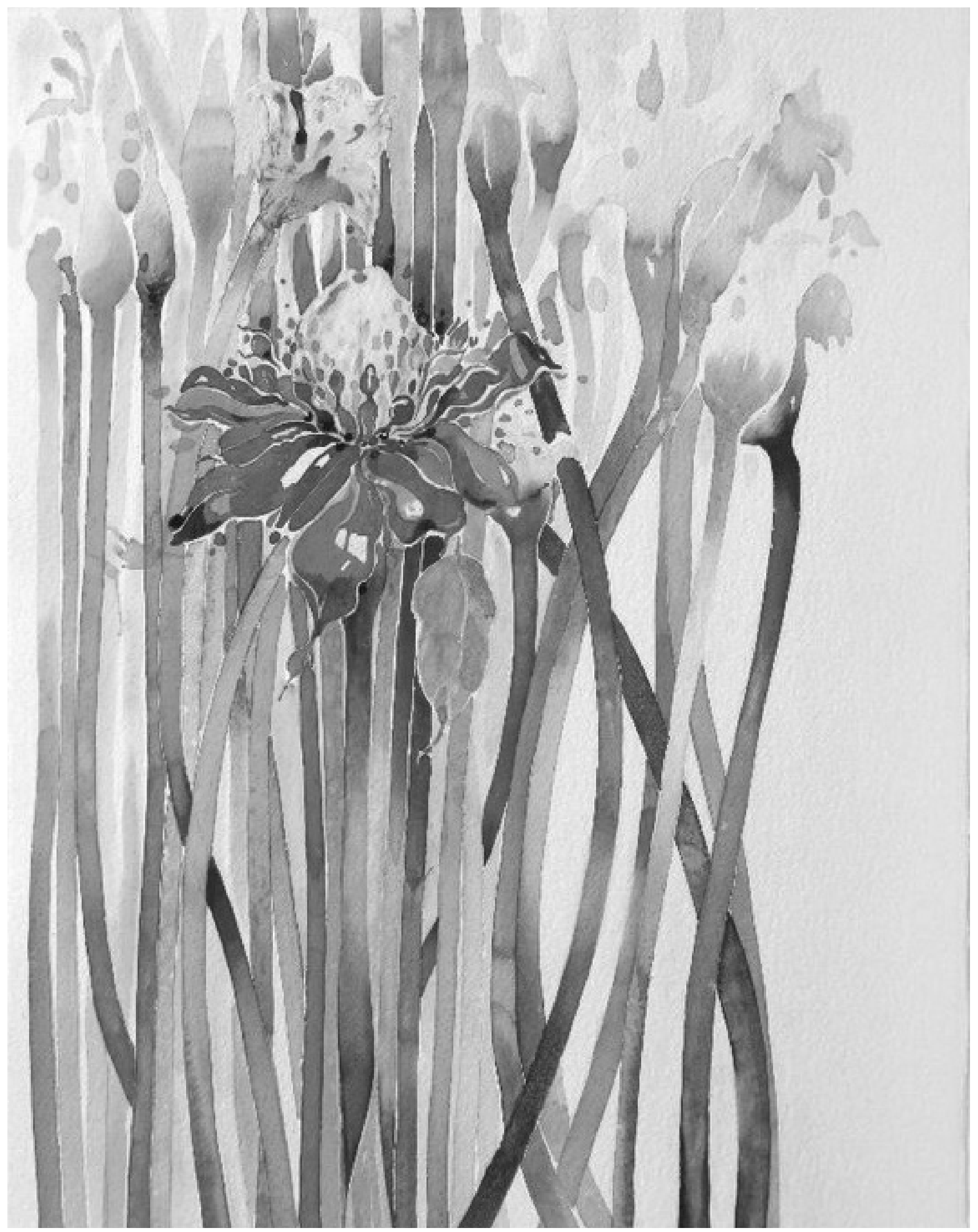


cotidianidad" según plantea el académico Rodríguez (2006, p. 114).

En todo caso, es una sutil retirada de sus postulados originarios. Recordemos que muchos años atrás, Alfonso Chase (1944) y Mía Gallegos (1953) abandonaron el "Círculo de Poetas Costarricenses" por diferencias de aesthesis. Hoy otros poetas han virado lentamente también, caso de Alejandra Castro (1974 - ), Juan Carlos Olivas (1986 - ), Gustavo Solórzano (1975 - ), Leda García (1951 - ), quienes en sus últimos poemas se acercan más a la cotidianidad y a la historicidad de sus enunciados, o al "culturalismo", aunque en principio se matricularan con el solipsismo trascendentalista. "Probablemente apelé a un público diferente" dice Solórzano en una entrevista acerca de su más reciente libro Inventarios mínimos (Carvajal, 2013).

En la miniguerrilla literaria, que alcanza a veces decibeles terroristas, el "conversacionalismo", la "antipoesía" o el "antilirismo", ocupan el sitio que le arrebataron a los trascendentalistas. Ejemplo de ello son los últimos premios de la Editorial Costa Rica (certamen Eunice Odio) y los Premios Nacionales que otorga el estado mediante el Ministerio de Cultura y Juventud en los cuales han sido favorecidos Alexander Obando (1958), Alfredo Trejos (1977), Luis Chaves (1969), David Cruz (1982), William Eduarte (1983) y Jonathan Lépiz Vega (1981). Igual sucede con las páginas de los principales medios físicos y virtuales. La formación discursiva dominante ahora es la conversacional, el Trascendentalismo ya no está de moda y por tanto no se concibe como "poesía oficial".

Queda por saber si la formación dominante obedece a un proceso de reacomodo de identidades locales (el hilo que hilvana la confusión histórica) o a una forma de acceder a la poesía global y globalizante. Mejor dicho: ¿obedece la poesía actual a un proceso histórico y social (la tradición y la ruptura) o a una estética e ideología colonizadas? ¿Obedecerá la poesía conversacional a un canon impuesto por la homogenización cultural inducida que padecemos, es decir, a una pésima (¿acaso cínica?) recepción del quehacer poético proveniente de las metrópolis sin un cernido desde acá? ¿Es una inversión o sustitución de los escenarios como antaño hiciera el modernismo en busca del cosmopolitismo, una nueva colonialidad del poder mediante el lenguaje?

Es tarea pendiente para la academia y la crítica en general precisar si la ruptura de la tradición obedece a fracturas de un proceso nacional, o si cede, más bien, a una transnacionalización lingüístico y literaria, específicamente poética. Es decir, determinar si la poesía costarricense contemporánea se somete a una recolonización de la palabra gracias a estilos "universales" que comparten cierta atmósfera cultural para satisfacer fórmulas metropolitanas. En otras palabras, para lograr que la periferia se presente como un producto cercano a lo que se promueve en el centro.

Por lo demás, resta un inmenso espectro de producción poética equidistante entre el Trascendentalismo y el antilirismo, o la antipoesía, del conversacionalismo en boga. Hay poetas de un realismo sucio mucho más radical, bizarro y torpedero que el inventariado y con una crítica visceral a la poesía como bellaletrismo (lo "aurático"), como el caso de Luis Yuré. También hay creadores escrutando rutas lejos de las formaciones discursivas hegemónicas en la diacronía de la producción poética nacional, aunque abreven y se refuercen con ambas (¿acaso sean Alfredo Trejos y Mauricio Molina los representantes más genuinos de esa bifurcación?). Sobre ello hay un vacío crítico sospechoso y lamentable. Habrá que retomar franjas ideoestéticas marginadas por un dualismo maniqueo que obvia la diversidad creativa de un país con claras asimetrías donde conviven múltiples maneras de aesthesis y variados espacios temporales (cronotopos) en el quehacer poético nacional.

\section{NOTAS}

1 Según Mignolo (2009) la aeshtesis puede entenderse como la naturaleza de los sentidos o de la percepción, de la "sensibilidad". El término fue acuñado por el pensamiento imperial a partir del siglo XVIII y evolucionó a "estética", es decir, el sentimiento de lo bello y lo sublime. Con el correr del tiempo lo sublime pasó a segundo plano y lo bello encadenó la estética, la cual quedó limitada al concepto occidental de "arte".

2 El aforismo lo define la Real Academia de la Lengua Española (2014) como una sentencia breve que procede generalmente de la experiencia y de la observación directa, ha sido utilizado por disciplinas que, en principio, carecían de una metodología de estudio o del método científico.

\section{REFERENCIAS BIBLIOGRÁFICAS}

Albán, L. (1977). Manifiesto Trascendentalista. Editorial Costa Rica, San José. 
Carvajal, S. (2013). La dulce nostalgia del nuevo poemario de Gustavo Solórzano-Alfaro. Obtenido el 8 de setiembre de 2014 del sitio http://redcultura.com/php/Articulos1125.htm

Durán Luzio, J. (1988). Un expediente humano y lírico. Suplemento Áncora. Periódico La Nación, domingo 21 de febrero.

Echeverría, A. (1998). Concherías. San José: Editorial EUNED.

Fernández, G. (2012). El antilirismo costarricense. Suplemento Áncora del periódico La Nación, del domingo 2 de setiembre. Recuperado el 2 de setiembre de 2012 desde http://www.nacion.com/2012-09-02/Ancora/El-antilirismocostarricense.aspx

Jiménez, G. (2013). Confrontación, dimes y diretes, y una peculiar discusión provocó artículo del poeta turrialbeño Marco Aguilar. Recuperado el 4 de setiembre de 2014 del sitio http://www.culturacr.net/13/03/La-poesia-costarricense-entro-en-conflicto.html\#.VPsnLHyUeSo

Jiménez, M. (1928). Unos fantoches. San José: Ediciones de El Convivio.

Jiménez, M. (1936). El Domador de pulgas. La Habana: Hermes.

Jiménez, M. (1978). Candelillas. San José: Editorial Costa Rica.

Jimenez, M. (2004). Obra literaria 1 y 2. San José: Editorial Costa Rica.

Lee Masters, E. (1916). Spoon River Anthology. Nueva York: Editorial MacMillan.

Mignolo, W. (2009). Desobediencia epistémica: Retórica de la modernidad, lógica de la colonialidad y gramática de la descolonialidad. Buenos Aires: Ediciones del signo.

Paz, O. (1974). Los hijos del limo. Barcelona: Editorial Seix Barral, S.A.

Rodríguez, F. (1996). Sobrevivencia del agua. San José: Editores Alambique.

Rodríguez, F. (2003). Tardes de domingo. San José: Ediciones Perro Azul.
Rodríguez, F. (2004). El ángel de la salmuera. San José: Ediciones Perro Azul.

Rodríguez, F. (2005). Serpigo. San José: Ediciones Perro Azul.

Rodríguez, F. (2006). Fauces. San José: Ediciones Arboleda.

Rodríguez, F. (2006). La formación discursiva trascendentalista en la poesía costarricense contemporánea. Revista Filología y Lingüística (XXXII), núm. 2, 107-119.

Rodríguez, F. (2006). La poesía costarricense contemporánea y el campo discursivo conversacional. Revista Káñina (30), núm. 2, pp. 145-161.

Rodríguez, F. (2007). El Sopor de la canícula. San José: Ediciones Arboleda.

Rodríguez, F. (2008). La penúltima estación. San José: Ediciones Arboleda.

Sánchez, C. (2003). Las esferas de la memoria. Heredia: Editorial EUNA.

Soto, J. (1985). Expediente. San José: Ediciones Chirripó.

Solórzano, G. (2010). Retratos de una generación imposible. San José: Editorial EUNED.

Solórzano, G. (2013). Inventarios mínimos. San José: EUNED.

Vargas Acuña, G. (2006). Identidad cultural y poesía en Pérez Zeledón. Revista Comunicación (15), núm. 2, 74-80.

Yuré, L. (2002). Tuanis Opus Palo. San José: Editorial No Hubo.

Yuré, L. (2002). Alba en rodajas. San José: Editorial Varitec.

Yuré, L. (2009). Fe de Ratas. San José: Editorial Germinal.

Yuré, L. (2010). Idiaykus. San José: Editorial No Hubo.

Zárate, M. (1999). La extensa huida. San José: Editorial Costa Rica. 